\title{
Spatial Characteristics of Residential Slums and its Impact on the Infrastructure System Services at the City of Najaf
}

\author{
Ahmed Abdul-Kareem Kadhim Al-Najim \\ Department of Tourism, Faculty of Administration and Economics, \\ University of Kufa, Najaf, Iraq, imad_dna@yahoo.com
}

\begin{abstract}
The study of residential slums in the holy city of Najaf considered as an extremely important issue for the great impact that it holds on the human life and his various activities and events. This influence reflected directly on the infrastructure system services which led to the weakness of its functional efficiency as well as their insufficient to the needs of the population. The reason for the spread of residential slums was due to several factors and reasons that helped them to form and grow, despite their negative effects, especially, infrastructure services such as transport routes, health, education and electrical power which led to the inadequacy of the population from the system service.
\end{abstract}

Key words: Residential slums, infrastructure services, urban environment, population, education, health, transport routes

\section{INTRODUCTION}

Research questions: The spread of residential slums outside the city's urban design represents an urban problem that directly affects the infrastructure services system, creating direct pressure which reduces its functional efficiency.

Hypothesis study: There are a number of factors affecting the residential slums in Najaf, especially, the problem of population growth, the imbalance of the housing units number along with the size of the population and the increase in unemployment rates in the urban space.

Study objectives: To know the geographical distribution of residential slums in Najaf and then reveal the factors and reasons that led to the spread of this phenomenon.

Spatial and temporal limits of the study: The spatial limits were represented in Najaf as shown in Fig. 1 for the purpose of studying residential slums while the time limit included 1 year which is (2018) during which the study has been conducted.

\section{Important concepts and terms}

Residential slums: Slums emerged in Najaf after 2003, right after the city was exposed to a large rural migration from the districts and districts in search of employment opportunities. Residential slums as those areas where housing has been constructed in a manner other than legal and planned within the basic design of the city, bypassing the laws governing urbanization and characterized by high population density and lack of public services and the spread of environmental pollution and diseases, moreover, it is the center of poverty due to poor living conditions.

Infrastructure services: They are part of institutions, commissions, buildings, networks and systems, designed to provide a service to a customer (population). Since, the nature of these activities requires a direct relationship with community members which constitutes an essential part of what so, called urban functions which include transport drinking water services, sanitation, electricity and communications (Ziadi, 2013).

The urban environment: The urban environment includes all aspects of human influence in order to create a human architecture with a homogeneous pattern that is governed by the spatial structure of its various elements and procedures. This interaction resulted from the interaction of human activities with the environmental nature in order to satisfy its needs and desires (Dulaimi, 2008). 


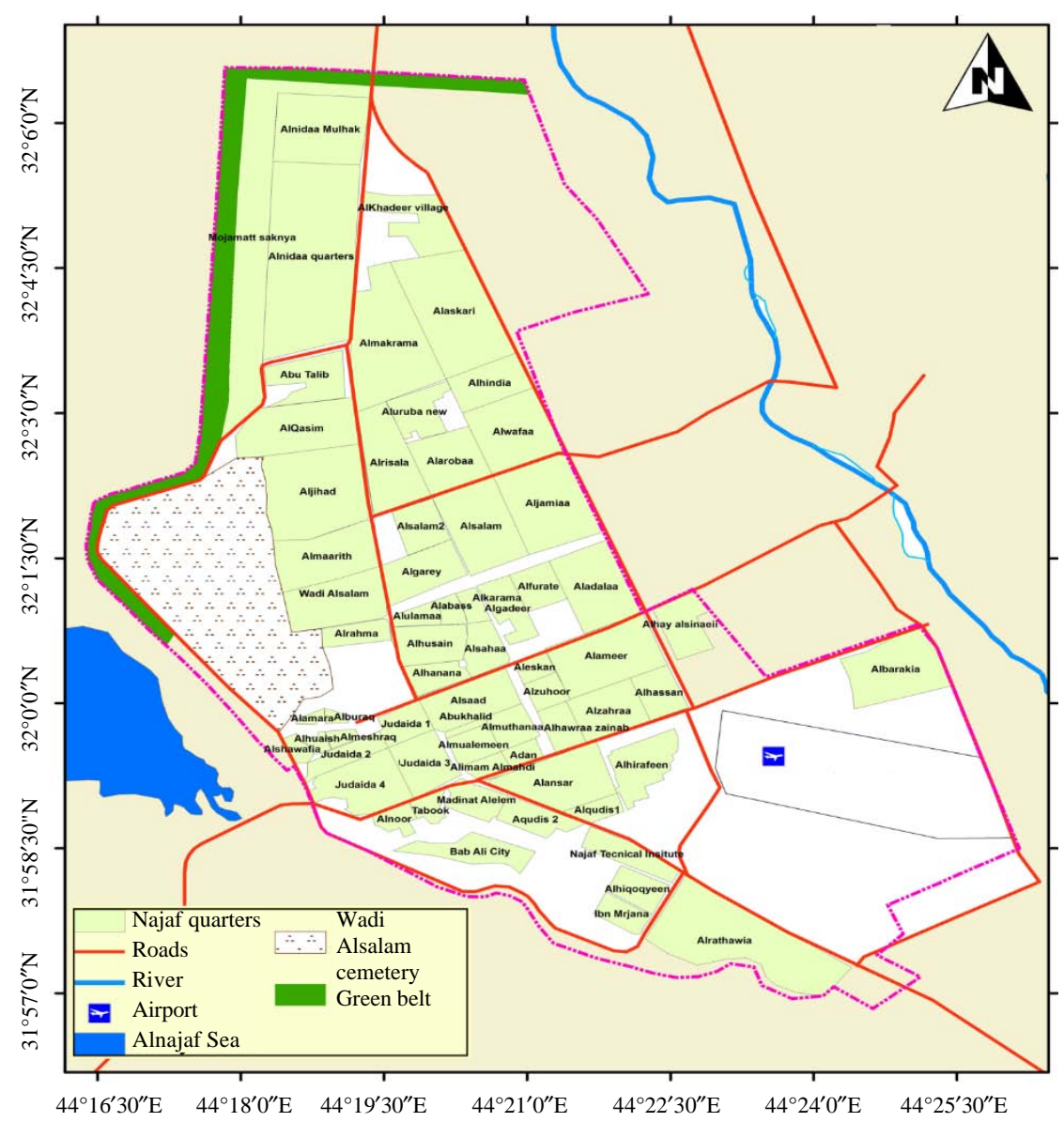

Fig. 1: Geographical location of Najaf. Republic of Iraq, Ministry of Municipalities and Public Works, Directorate of the Municipality of Najaf Governorate, basic design 2018

\section{MATERIALS AND METHODS}

Factors affecting the spread of residential slums in Najaf: Population growth and its demographic implications on the urban society. The change in the size of the population is called population growth, population growth as a demographic concept does not mean the numerical increase of the population only but rather the increase or decrease in the population. The source of population growth stems from three main factors: births, deaths and migration (Al-Hasnawi, 2007). As well as the increase in the size of family results in negative effects, such as socialization, aggressive behavior and family violence. Which is reflected clearly on children (Brichey, 2014).

The relationship between the size of the family and the standard of living of the poor family is illustrated by the number of children as the economic situation is proportional to the size of the family and the number of children (Akkila, 2013). These changes have a significant impact on the economic structure of the community members and what is associated with its plans and strategies to ensure investment of natural resources and human investment to achieve the required benefit (Al-Jabbar, 2012). The population of Najaf city in 1947 , reached (56362) people and in 1957, the population reached (89193) people and an increase of (32831) people with a rate of population growth reached (4.6) with a percentage of $(36.8 \%)$. The population censuses indicates the continued constant increase which reached in 1957, (89193) people while in 1965, the total population amounted (134127) people with a growth rate of (4.1) with absolute increase amounted (44934) people and a percentage of $(33.5 \%)$ as in Fig. 2. The population continued to increase in Najaf for the period (1977-1965), (52452) people and the rate of population growth reached (3.3). While during the period (1977-1987), the population reached (118252) people with a rate growth estimated 


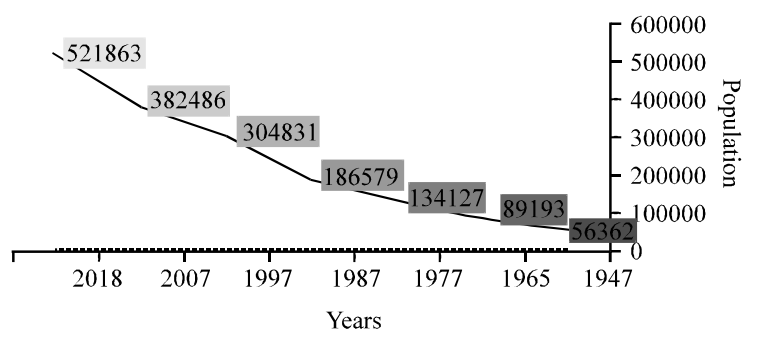

Fig. 2: Republic of Iraq, Ministry of Planning and Development Cooperation, Central Organization for Statistics and Information Technology, Statistical Group for the period (1947-2018); Evolution population size and growth rates and absolute change in the city of Najaf for the period (1947-2018)

(5.0) and a percentage of $(38.8 \%)$ while the population increased during the period (1987-1997) with an estimate of (77655) people with a rate growth reached (2.2) and a percentage of (20.3\%). During the period (1997-2007) population increased to (139377) people with a growth rate of (3.1) and by (26.7\%) while the population increased during the period (2007-2018), to an amount of (75780) and a rate growth population reached (1.2) with a percentage of $(12.7 \%)$. The proper justification for the increase in population and its relation to urban poverty lies in the lack of adequate level of infrastructure services within the city which made most of the population do not get the services they need to meet their needs and life requirements. In addition, there is non-investment of qualified human resources in the labor market. Nevertheless, the economic development requires economic and social transformations and structural changes that increase the income of the individual (Amara, 2012).

Unbalance of housing units with population size: Providing housing units and their services is a key priority to fight spreading of residential slums and preserving environment as well as the original urban features. The total number of housing units in Najaf is (101789) units, reaching (34965) housing units within the urban center of the city, moreover with a population size reached double of the housing units number with an estimated number of (174831) and with an area of (552.9 ha) while the population density reached (316.20) person/ha. housing units number reached (19879) in the residential slums, this kind of housing units is specialized with irregularity in space, design and Foreign decorations which led to a clear urban distortions. As well as the infrastructure services limited availability, these are characterized by high population size reached (163052) housing units while the residential area reached (544.8 ha) with a population density of (299.28) person/ha. While
Table 1: The relative distribution of the unemployment rate at the age of 15 years and more in the city of Najaf in 2018

\begin{tabular}{llll}
\hline City of Najaf & Female & Male & Total \\
\hline Unemployment rate & 38.2 & 36.4 & 74.6 \\
\hline Field study on $2 / 1 / 2018$ & & &
\end{tabular}

the number of housing units in the Northern districts extended to (28969) housing unit with a population size of (118507) in a residential area (884.4 ha). While the residential density reached (133.99) ha/person in addition, the contact between the Northern neighborhoods in Najaf with the Najaf-Karbala Road, that encouraged residents to move towards residential complexes that emerged recently, such as Al-Ghadeer village, Al-Aamerat residential complex and Qanbar residential complex. The number of housing units extended to (17976) in the southern neighborhoods in addition, the housing units of the population size reached to (141253) people while the residential area reached (4263.1 ha) and the residential density (33.133) person/ha. It is clear that there is a real crisis of settling in Najaf, through the presence of high demand from the population on providing houses without an increase in the number of housing units.

Unemployment increase in the urban space: Increasing the number of workers in the production of goods and services without the use of their skills and knowledge creates an economic problem within the urban society (Sameh, 2002) which emerged as a result of the lack of jobs that provide works and the proper. On the other hand, the increase in population is not planned, through either birth or migration from the countryside, Table 1 shows the unemployment rate in the residential slums that reached $(74.6 \%)$ and female ratio topped the first place with a percentage (38.2\%) while males came in the second place with a percentage of $(36.4 \%)$ (Field study on 2/1/2018).

Geographical distribution of housing slums in the city of Najaf: The slums or so-called "degraded areas" which are common among the population, lack social cohesion and lack the most basic services and suitable housing as well as lack of infrastructure services (potable water, electricity, paved roads and other basic services) (Jabir, 2006).

Figure 3 shows the geographical distribution for residential slums in Najaf which reached 6, neighborhoods which they are:

Al-Rahma District with an area of ( $52 \mathrm{ha}$ ) which is an industrial and storage area. This residential neighborhood is located near the valley of peace cemetery. Al-Radwiya neighborhood which is (32.28 ha). This neighborhood is located in the Southern neighborhoods on the Najaf-Diwaniya Road. 


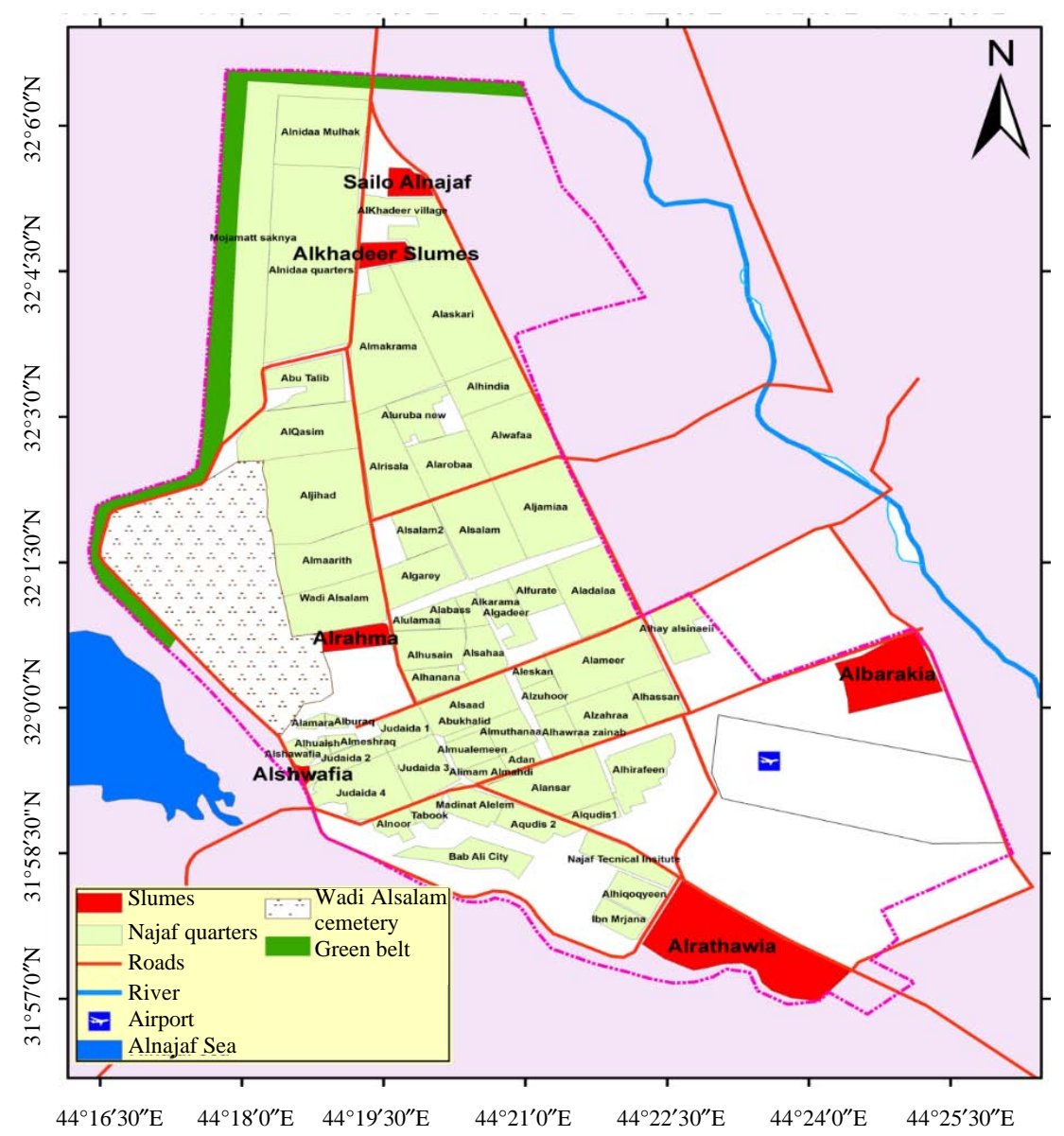

Fig. 3: Geographical distribution of residential slums in Najaf. Republic of Iraq, Ministry of Municipalities and Public Works, Directorate of the Municipality of Najaf Governorate, basic design 2018

Najaf Sailo area which it is about (119.12 ha) located within the Northern neighborhoods of Najaf. Al-Barakiah with an area of (264.54 ha), it is agricultural land located behind the Najaf International Airport and extend its geographical reach to the city of Kufa.

The area which is near to Al-Ghadeer village of residential and is among the irregularities with an area of (45.63 ha). Al-Shawafaa and part of Al-Jediadat. This area is located behind the old city and occupies an area of (31.23 ha).

\section{Characteristics of Najaf's urban environment in the} residential slums: The urban environment in Najaf witnessed rapid and comprehensive changes. These changes included the demographic, social, economic and physical aspects, the result of these changes were many effects represented in the expansion of urban environment in a random way (Hakim, 1980). The following address urban environment.

\section{RESULTS AND DISCUSSION}

Housing ownership: The problem of housing is the outcome of many years of neglect and unhealthy planning, it is not just but it is a life problem but it is also a civilization problem. The residential units in the residential slums is characterized by heterogeneity and the existence of multiple differences of in terms of shape and size. Moreover, it is considered as a clear indication of economic and social level to the family and the human being, due to the existence of this distinction and differences between the housing units in the residential slums which puts direct pressure on infrastructure services. Most of the residents do not have a proper land to settle in as a result to the high prices of lands and the unsuitable planning in a way that covers the current and future needs of the population. Which led to the aggravation of this problem in an 
increased way that reached slums $(38.3 \%)$ in which they are unplanned land outside the basic design of the city.

\section{Negative effects on the expansion of residential slums in} the city: Daily movement systems for residential slums. The road networks in the residential slums forms a system characterized by irregularity and unbalanced deviation which is a distorted visual scene due to the inappropriate use of the land to each other, some roads are with closed ends which leads to distortions in road services (Ameri, 2007).

The spread of diseases and the lack of health services in residential slums: There are several reasons for the spread of diseases in residential slums, the most important of which is the polluted environment which is full of microbes, bacteria and the wastewater which made the infection rate to a high level by infection among children reached to $(19.6 \%)$. The second factor is the lack of financial capacity of treatment with a percentage of $(18.2 \%)$, there is insufficient treatment in hospitals and health centers. The third factor is the failure to follow a diet and by a percentage reached to $(17 \%)$ due to the low health awareness of most households in residential slums. Moreover, aging reached $(13.8 \%)$, the fifth factor was immune decline for most family members, leading to the increase in disease severity in addition, the sixth factor is the genetic one with a percentage of $(10.5 \%)$ (Field study on $3 / 5 / 2018$ ).

Problems of drinking water in residential slums: In order to make the process of analysis accurate and scientific, we relied in our analysis on several indicators of drinking water. The results of the Ministry of Water Resources showed that the drinking water projects suffer from obvious application problems, namely, the lack of adequate drinking water projects. The value of this indicator reached $(40.9 \%)$ while the second indicator is the water the lack of rains in the study area accompanied by a decline in the water level, reached to $(68.2 \%)$. The total water pollution index value reached to $(36.4 \%)$ during the examination of samples from the waters of Euphrates (Kufa river) due to the high solid wastes of human activity which increases over time (Al-Zuhairi, 2008). Industrial pollution resulting from the chemical, food, textile and construction industries as well as pollution resulting from the activities of the city such as solid waste that is not solved in the right environmental ways (Battat, 2009). Household wastes is composed of dissolved organic matter that is hosted in the Kufa water and Abbasiat water from the sewage waste as well as the nutritious salts which are naturally formed due to the high rates of water pollution (Asadi, 2008).

Low electricity services for residential slums: The low power supply in residential slums has been reflected in the overall life of the population in particular, the hours of shutdown has exceeded to $270 \mathrm{~h} /$ day. This shows the rise of hours of electrical parts, especially, in summer season due to poor electric power, leading to extinguishing most of the electrical appliances inside the housing units. This has a problem of social, psychological and economic damage to the members of the community which prompted the population to participate in civil generators to compensate for the hours of electric cutting (Al-Obaidi and Ahmed, 2009).

Lack of sanitation services in the residential slums: Residential slums suffers from the lack of sewage networks. There we find a shortage in the efficiency of sewage services estimated to $(75 \%)$ of the actual need. As well as the lack of networks suitable to the amounts of the falling rain which makes these areas to collect water in the form of pools, causing great damage to the community, especially, the spread of diseases and environmental pollution (Al-Zuhairi, 2008).

Poor efficiency of telecommunications services in the residential slums: As long as these residential slums is outside the basic design of the city, they suffer from a clear lack of internet services as a result of the lack of towers that is specified for the transfer of internet signal as well as the communications interruption during specific hours during the day which caused a real problem to the population.

\section{CONCLUSION}

The study reached a number of scientific results in the study of residential slums, mainly it is the absence of planning standards in developing the major plan in Najaf, as well as the lack of legal controls working in the preservation of the urban fabric of the city which they prevent the spread of residential units scattered within agricultural lands. These negative issues caused another problem, which is the pressure on the system of infrastructure services which led to a decline in efficiency and functional inability to satisfy the needs and desires of the population. 


\section{REFERENCES}

Akkila, E.Z., 2013. Impact of living standards on health and education services. Master Thesis, Islamic University of Gaza, Gaza.

Al-Hasnawi, J.K., 2007. The population distribution of Saladin and Nineveh governorates for the period (1977-1997). J. Babel Univ. Hum., 2: 1-1.

Al-Jabbar, M.H., 2012. Spatial analysis of population growth in Najaf governorate for the period (1997-2011) and its future effects. Master Thesis, Girls College of Education, Kufa University, Kufa, Iraq.

Al-Obaidi and S.S. Ahmad, 2009. Analysis of spatial variation of infrastructure services (water, sewerage, electricity, landline) for the city of Karbala using GIS technology. Ph.D Thesis, Ibn Rushd College, University of Baghdad, Baghdad, Iraq.

Al-Zuhairi, M.S.H., 2008. Future assessment of the efficiency performance of wastewater treatment plants in Baghdad. Tech. J., 21: 1-1.

Amara, N., 2012. Population growth and sustainable development (case study of Algeria). Master Thesis, Badji Mokhtar University, Annaba, Algeria.

Ameri, M.A.H., 2007. The impact of urban transport in the functional construction and urban expansion of the city of Diwaniya (study in Urban Geography). Master Thesis, University of Al-Qadisiyah, Al Diwaniyah, Iraq.

Asadi, K.S., 2008. Effect of sewage waste on surface water pollution in Najaf Governorate. J. Hum. Sci., 11: 1-1.
Battat, M.F., 2009. Water pollution in Iraq and environmental impacts. Qadisiyah J. Manage. Econ. Sci., 11: 1-1.

Brichey, A., 2014. The role of tax in the redistribution of national income case study of Algeria during the period (1988-2011). Ph.D Thesis, University of Abou Bekr Belkaid, Tlemcen, Algeria.

Dulaimi, A.J.M.D., 2008. Urban expansion and its impact on agricultural land in the Rural City of Khalidiya. Master Thesis, University of Anbar, Ramadi, Iraq.

Hakim, M.S., 1980. Growth and Urbanization in the Arab World, Arab Organization for Culture and Science. Arab League, Cairo, Egypt,.

Ibrahim, Z.A.A.M., 2012. Slums from the point of view of residents of nearby urban areas research anthropological study in the district of Sumer Baghdad. Master Thesis, University of Baghdad, Baghdad, Iraq.

Jabir, M.M., 2006. Geography of Urban and rural urbanism. The Anglo-Egyptian Sudan, Sudan, North Africa.

Rabeh, S., 2006. Social life in the new urban spaces, the urban area of Bonne Annaba. Master Thesis, Humanities and Social Sciences, Badji Mokhtar University, Annaba, Algeria.

Sameh, A.W., 2002. Unemployment in the urban complex of greater Cairo. Master Thesis, Cairo University, Giza, Egypt.

Ziadi, A.M.A.A., 2013. Spatial analysis of the infrastructure of Najaf Al-Ashraf. Master Thesis, University of Mustansiriya, ?Baghdad, Iraq. 